
Revue Revue de l'histoire des religions
de Ihistoire des religions
Judaïsme / christianisme : syncrétismes, antinomies, dissonances

Thierry AMALOU, Une concorde urbaine: Senlis au temps des réformes (vers 1520-vers 1580)

Limoges, Pulim, 2007, 437 p., $28 €, 24$ cm, ISBN 978-2-84287-437-7

Mickaël Wilmart

\title{
OpenEdition
}

Journals

Édition électronique

URL : http://journals.openedition.org/rhr/7873

DOI : $10.4000 /$ rhr.7873

ISSN : $2105-2573$

Éditeur

Armand Colin

Édition imprimée

Date de publication : 1 mars 2012

Pagination : 146-147

ISSN : 0035-1423

Référence électronique

Mickaël Wilmart, «Thierry amalou, Une concorde urbaine : Senlis au temps des réformes (vers 1520-vers 1580) », Revue de l'histoire des religions [En ligne], 1 | 2012, mis en ligne le 04 avril 2012, consulté le 22 septembre 2020. URL : http://journals.openedition.org/rhr/7873; DOI : https://doi.org/10.4000/rhr. 7873

Ce document a été généré automatiquement le 22 septembre 2020.

Tous droits réservés 


\section{Thierry AMALOU, Une concorde urbaine: Senlis au temps des réformes (vers 1520-vers 1580)}

Limoges, Pulim, 2007, 437 p., $28 €, 24$ cm, ISBN 978-2-84287-437-7

\section{Mickaël Wilmart}

\section{RÉFÉRENCE}

Thierry AMALOU, Une concorde urbaine : Senlis au temps des réformes (vers 1520-vers 1580),

Limoges, Pulim, 2007, 437 p., $28 €, 24$ cm, ISBN 978-2-84287-437-7.

1 Comment Senlis, ville moyenne d'île-de-France, ne cède pas aux passions de son temps et évite de basculer dans les violences religieuses du xvi siècle, alors qu'au même moment Meaux, sa voisine, se déchire entre protestants et catholiques ? C'est à cette question que Thierry Amalou répond dans ce livre exemplaire où l'érudition et la fine connaissance de l'historiographie sont renforcées par un impressionnant travail en archives qui va bien au-delà du cadre senlisien. L'auteur a non seulement dépouillé minutieusement les sources concernant Senlis mais également poursuivi une enquête de première main à Crépy-en-Valois, Meaux ou Provins et lu la plupart des récits des contemporains. Il offre ainsi au lecteur une histoire urbaine dont l'approche multiple, à la fois politique, sociale et religieuse, permet de comprendre les processus débouchant sur la préservation d'une concorde qui n'allait pas de soi.

2 En effet, Senlis est précocement touchée par la réforme protestante. Dès 1532, l'évêque est contraint de faire intervenir l'Inquisition dans sa cité. Cinq hommes sont interrogés et dressent le portrait d'une première communauté de "Bibliens ", suffisamment organisée pour se réunir en conventicules ou pour oser quelques prédications. Leurs influences sont diverses et leurs positions semblent plus radicales que le luthéranisme et sont parfois proches des sacramentaires zwingliens. Leur surgissement sur la scène publique est concomitant d'un effritement communautaire qui se manifeste par une 
baisse des œuvres charitables et des fondations, l'affirmation d'un certain anticléricalisme et le déclin des confréries. Dans les années 1540, l'influence calvinienne prend le dessus et une nouvelle communauté, toujours très minoritaire, se met en place en liaison avec celle de Meaux qui est réprimée par le bûcher en 1546. Le groupe réformé senlisien s'organise en église avec son ministre et ses anciens, s'approprie le texte biblique et tient régulièrement des assemblées en plein air. Il faut attendre 1560 pour le voir inquiété par l'officialité avant l'arrestation massive de protestants par la municipalité en juin 1562. Passé 1563, la ville ne connaît plus de troubles et refuse même en 1577 de se rallier à la Ligue.

3 Pour expliquer ce non-basculement, Thierry Amalou a choisi de reconstituer le contexte municipal et diocésain qui a favorisé la concorde dans une ville pourtant touchée par l'hérésie. Dotée d'une autonomie urbaine restreinte héritée de la période médiévale, au début du xvi ${ }^{\mathrm{e}}$ siècle la ville est sous le contrôle, plus ou moins serré, des officiers royaux. Même pendant les entrées royales, moments-clés de l'orgueil civique, les échevins restent au second plan. L'échevinage est alors le privilège d'une oligarchie, puisque réservé aux marchands et officiers nés à Senlis. Il est également monopolisé par un petit nombre de familles. Cependant, dès 1545, des horsains sont élus échevins et après 1547, la ville est l'une des rares à appliquer l'édit interdisant l'échevinage aux officiers. Il est évident que cette crise municipale renforce la crise communautaire à l'origine de l'apparition de la dissidence religieuse.

4 En fait, la cohésion urbaine doit sa sauvegarde aux pratiques dévotionnelles collectives. L'auteur signe à ce propos un chapitre fort intéressant sur le culte des reliques dans une ville véritablement vécue comme un sanctuaire par les contemporains, se rattachant par ses objets de dévotions à la dynastie royale. Enfin, le culte de saint Rieul, et surtout la réaffirmation de son apostolicité puisque disciple de saint Denis, est le garant d'une tradition catholique face à la montée dissidente. L'évêque Guillaume Parvi fait ici œuvre d'une véritable recharge sacrale, pour reprendre un terme cher à Alphonse Dupront, et poursuit l'idéal sacerdotal mis en place par Artus Fillon dans le même esprit que le cénacle regroupé autour de Guillaume Briçonnet à Meaux. Mais alors que dans la cité briarde, certains éléments comme Guillaume Farel radicalisent leur prédication et préparent le terrain à la montée d'une réforme protestante solidement ancrée, le travail des ecclésiastiques senlisiens semble porter ses fruits. D'un côté, le chapitre cathédral s'attèle au renforcement de la piété mariale et au développement d'une piété christocentrique. D'un autre côté, l'action de "moyenneurs" comme le théologal Nicolas Martimbos, prônant la réforme dans l'unité, est sans doute pour beaucoup dans la faible propagation de l'hérésie qui touche toutefois des classes sociales diverses, des artisans aux officiers dont certains sont arrêtés en 1562.

5 Le retour des gens de justice à l'échevinage en 1564 ouvre la voie à une politique de tolérance civile dont l'application est facilitée par l'absence de traumatisme comme l'iconoclasme huguenot. En mettant en avant le bien commun et l'intérêt de la ville, les officiers siègent de nouveau à l'hôtel de ville. Par là, ils montrent aussi leur attachement à la ville, en dépit de la répression de 1562. Dotés parfois d'une véritable érudition humaniste, comme Guillaume Durand aux affinités érasmiennes affirmées, ils contribuent à l'instauration d'une nouvelle vie municipale, réformant la police, l'assistance ou les structures éducatives, dans un véritable projet d'harmonie sociale. Soutenu dans ses efforts par François de Montmorency, qui lui obtient de nouveaux 
privilèges, Senlis vit désormais à l'heure de la temporisation civique et religieuse, évitant une Saint-Barthélemy et refusant d'adhérer à la Ligue de 1577.

6 Si une concorde urbaine s'instaure, c'est parce qu'un parti moyenneur a pu prendre le dessus et mettre en avant une raison de ville, comme l'avait déjà démontré pour le Limousin Michel Cassan. En couplant une approche d'histoire politique, concentrée sur les institutions municipales et leur composition sociale, avec une anthropologie religieuse renforcée de fines descriptions, Thierry Amalou livre ici une contribution exceptionnelle à l'histoire religieuse du Xvi ${ }^{\mathrm{e}}$ siècle.

\section{AUTEURS}

\section{MICKAËL WILMART}

École des Hautes Études en Sciences Sociales. 